\title{
BMJ Open Publication status of completed registered studies in paediatric appendicitis: a cross-sectional analysis
}

\author{
Thomas Breil, ${ }^{1}$ Michael Boettcher, ${ }^{2}$ Georg F Hoffmann, ${ }^{1,3}$ Markus Ries ${ }^{3}$
}

To cite: Breil T, Boettcher M, Hoffmann GF, et al. Publication status of completed registered studies in paediatric appendicitis: a crosssectional analysis. BMJ Open 2018;8:e21684. doi:10.1136/ bmjopen-2018-021684

- Prepublication history for this paper is available online. To view these files please visit the journal online (http://dx.doi. org/10.1136/bmjopen-2018021684).

Received 11 January 2018 Revised 11 June 2018 Accepted 12 June 2018

A) Check for updates

(c) Author(s) (or their employer(s)) 2018. Re-use permitted under CC BY-NC. No commercial re-use. See rights and permissions. Published by BMJ.

${ }^{1}$ Pediatric Gastroenterology and Hepatology, Center for Pediatric and Adolescent Medicine, Heidelberg University Hospital, Heidelberg, Germany ${ }^{2}$ Pediatric Surgery, University Medical Center HamburgEppendorf (UKE), Hamburg, Germany

${ }^{3}$ Pediatric Neurology and Metabolic Medicine, Center for Pediatric and Adolescent Medicine, Heidelberg University Hospital, Heidelberg, Germany

Correspondence to

Professor Markus Ries;

markus.ries@uni-heidelberg.de

\section{ABSTRACT}

Objective Appendicitis is considered the most frequent surgical emergency in children. While the management of paediatric appendicitis is evolving, the precise amount of unpublished completed trials, potentially introducing bias into meta-analyses, is unknown. Controversial issues include the appropriate choice of surgical procedures, criteria for diagnosis of appendicitis, the role of antibiotic treatment and pain management. Selective reporting may introduce bias into evidencebased clinical decision-making, and the current, precise extent of unpublished results in paediatric appendicitis is unknown. We therefore assessed the publication status of completed clinical studies involving children registered on ClinicalTrials.gov.

Design Cross sectional analysis. STrengthening the Reporting of OBservational studies in Epidemiology criteria were applied for design and analysis.

Setting and participants ClinicalTrials.gov was queried for completed studies which were matched to publications on ClinicalTrials.gov, PubMed or Google Scholar. If no publication could be identified, principal investigators were contacted.

Interventions/exposure Observational analysis. Primary and secondary outcome measures The proportion of published and unpublished studies was calculated. Subgroup analysis included studies on surgical procedures, diagnosis, antibiotic treatment and pain management.

Results Out of $n=52$ completed clinical studies involving children with appendicitis, $n=33(63 \%)$ were published and $n=19(37 \%)$ were unpublished. Eightythree per cent $(n=43 / 52)$ of clinical trials assessed the above-listed controversial issues. Diagnostic studies were most rigorously published $(91 \%$ of trials reported), data on surgical procedures, antibiotic and pain management were less transparent. Sixty-six per cent of interventional studies and $60 \%$ of randomised studies were published. Median time-to-publication, for example, the delay between completion of the trial until public availability of the results was 24 (IQR 12-36), range 2-92 months.

Conclusion Despite the importance of appendicitis in clinical practice for the paediatric surgeon, there remains scientific uncertainty due to unpublished clinical trial results with room for improvement in the future. These data are helpful in framing the shifting paradigms in paediatric appendicitis because it adds transparency to the debate.

\section{Strengths and limitations of this study}

This is the first study analysing reporting transparency in clinical research of paediatric appendicitis.

- Clinical trial registration databases other than ClinicalTrials.gov were not analysed.

- Unregistered clinical studies were not captured by the present study method.

\section{INTRODUCTION}

Appendicitis is considered the most frequent surgical emergency in children with an incidence of 86 cases per 100000 people. ${ }^{12}$ Efforts are increasing to standardise diagnosis and management, nevertheless controversies continue to exist and challenges remain. ${ }^{3}$ Although a variety of scoring systems have been developed, ${ }^{4-6}$ there is still no unequivocal consensus on clinical, laboratory and imaging criteria for diagnosing appendicitis. After the diagnosis is made, usually surgical intervention follows. Recent studies have demonstrated that non-operative management for carefully selected children with acute appendicitis is possible. ${ }^{7-9}$ Different surgical approaches exist: over the years, laparoscopic appendectomies have widely replaced open traditional procedure. ${ }^{10}$ Many surveys compare different minimally invasive techniques finding no relevant differences in outcome between three-port or single-incision appendectomies. ${ }^{11}{ }^{12}$ Optimisation of pain management in children with appendicitis has recently become the centre of several investigations. ${ }^{13} 14$

Selective reporting of clinical trial results introduces bias into evidence-based clinical decision-making. ${ }^{15-17}$ The precise extent of bias in paediatric appendicitis is unknown. We therefore assessed the public availability of study results of completed clinical studies involving children with appendicitis registered in the major clinical trial database. We drew particular attention on studies focusing on important controversial issues, that is, 
surgical procedures, diagnosis of appendicitis, antibiotic treatment and pain management. The aim of this study is to render the current publication status of completed, registered, clinical trials in appendicitis involving children transparent.

\section{METHODS}

We determined the proportion of published and unpublished results of studies on paediatric appendicitis that were registered and reported as 'completed' on ClinicalTrials.gov.

ClinicalTrials.gov database query www.clinicaltrials.gov was accessed through the internet. The detailed search criteria were: keyword 'appendicitis' and ClinicalTrials. gov query selection parameters 'completed studies' and 'child'. Data were downloaded.

\section{Search for publications of completed studies}

ClinicalTrials.gov, PubMed and Google Scholar were searched for publications related to the completed registered paediatric studies on appendicitis identified as described above. Keywords for literature research included the NCT number, study title as listed in ClinicalTrials.gov or semantic keywords generated from study title as listed in ClinicalTrials.gov, place of study or principal investigator. If no publication could be found on PubMed or Google Scholar as a next step principal investigators or sponsors were contacted directly and asked to provide the publication of the study to make sure that no published study is missed (see the flow sheet in figure 1). All investigators of unpublished studies $(n=19)$ listed in ClinicalTrials.gov were contacted by email, $n=5$ replied, none provided published study results. Close of database for the search in each repository was 3 May 2016.

\section{Statistical analysis}

The following continuous or categorical variables were considered: NCT number, study title, gender and age of participants, study type, study design, condition, intervention, recruitment status, completion date, availability of study results, publication date, sponsor/collaborator and country of sponsor/collaborator. The purpose of clinical studies or the intervention was analysed and trials were categorised into five groups according to their major

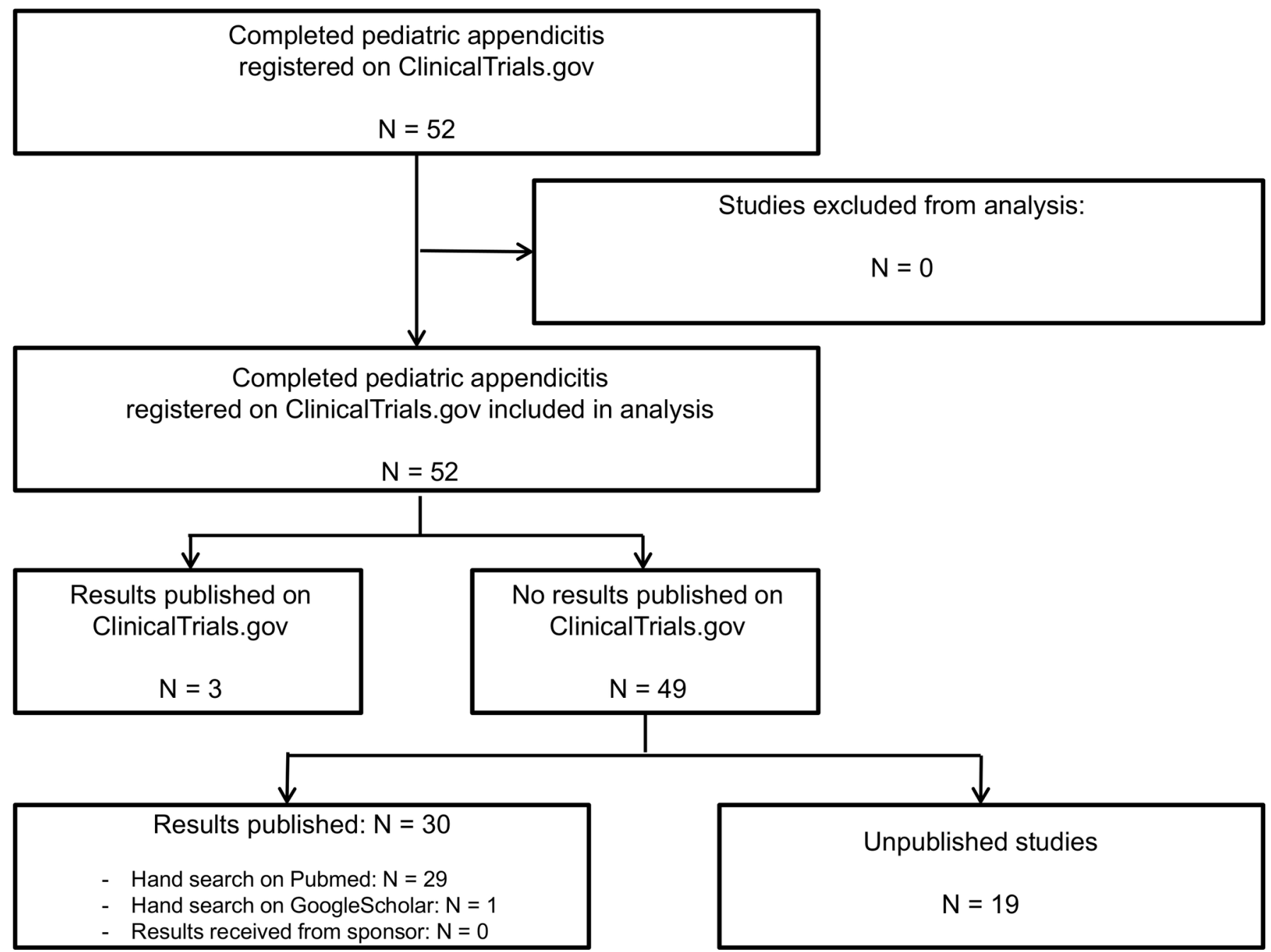

Figure 1 Study flow diagram: identification of published and unpublished clinical trials registered on ClinicalTrials.gov involving children with appendicitis. 


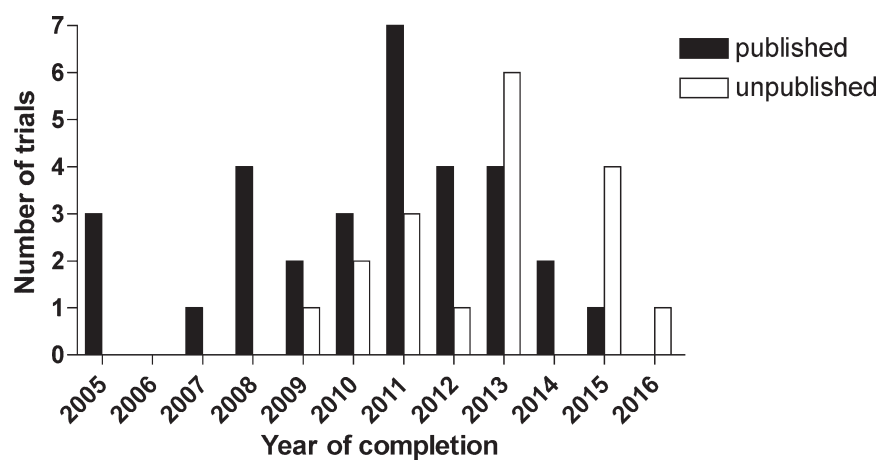

Figure 2 Published and unpublished paediatric appendicitis studies: number of trials by year of completion.

research topic: (1) surgical procedures, (2) diagnostic criteria, (3) antibiotic treatment, (4) pain management and (5) other.

Time-to-publication was calculated as the difference in months between publication date and completion date.

Standard methods of descriptive statistics were applied. Missing data were not imputed. All calculations were performed with SAS Enterprise Guide V.5.1.

STrengthening the Reporting of OBservational studies in Epidemiology criteria were applied for design and analysis of this cross sectional study. ${ }^{18}$ Close of database was 3 May 2016. A study flow sheet is provided in figure 1.

\section{Patient involvement}

Patients were not involved in this research project.

\section{RESULTS}

\section{Publication status of studies and trial participants}

Overall, we identified $n=52$ completed clinical studies on appendicitis involving children registered on ClinicalTrials.gov. Out of those, $n=33(63 \%)$ studies were published and $\mathrm{n}=19(37 \%)$ studies were unpublished (figure 2, table 1, tables 2A,B). Published trials contained data from $n=11997$ study participants. The unpublished trials embody information from $n=98673$ patients (figure 3). Median size of published trials was 150 (IQR 73-360), range 21-4000 patients whereas median size of unpublished studies was $\mathrm{n}=184$ (IQR 82-500), range 2-40 000 participants. Three unpublished studies were outliers and had 15000 (one study) and 40000 participants each (two studies). Year of completion ranges from 2005 to 2016. Out of $n=23$ observational studies, $\mathrm{n}=14(39 \%)$ were published and out of $\mathrm{n}=29$ interventional studies, $\mathrm{n}=19(66 \%)$ were published. $\mathrm{n}=25$ studies were randomised trials. Out of those, $\mathrm{n}=15(60 \%)$ were published and $\mathrm{n}=10(40 \%)$ remained unpublished. The published randomised studies contained data of $n=2461$ patients, the unpublished studies recruited 1411 patients. All studies involved both genders. The difference in publication rates by country of sponsor/collaborator is shown in table 3 .

\section{Time to public availability of results}

Median time-to-publication, that is, the delay from completion of the trial until public availability of the data was 24 (IQR 12-36) range 2-92 months. More recent studies tended to be published faster than older studies (figure 4).

Six studies were completed less than 1 year before close of database. Of those, only one study was published (tables 2A,B). This study, a comparison of surgical versus antibiotic therapy, for appendicitis had positive results and was published within 8 months after completion.

\section{Study sponsors}

Three studies were sponsored or cosponsored by the industry. All these studies were published. All other studies were sponsored by academia.

\section{DISCUSSION}

In order to render clinical research transparency, the AllTrials initiative (www.alltrials.net) called for registration and publication of all results of all clinical trials. In addition, publication of clinical research data is considered an ethical imperative. ${ }^{19}$ In 2007 , the prospective registration and mandatory publication of applicable clinical trials within 1 year of completion became federal law in the USA with the Food and Drug Administration Amendments Act (FDAAA).$^{20}$

Table 1 Publication status of studies registered as completed on ClinicalTrials.gov involving children with appendicitis

\begin{tabular}{|c|c|c|c|c|c|}
\hline Issue & $\begin{array}{l}\text { Overall } \\
\text { number of } \\
\text { studies }\end{array}$ & $\begin{array}{l}\text { Number and } \\
\text { percentage of } \\
\text { published studies }\end{array}$ & $\begin{array}{l}\text { Number and } \\
\text { percentage } \\
\text { of published } \\
\text { randomised studies }\end{array}$ & $\begin{array}{l}\text { Number of } \\
\text { patients enrolled in } \\
\text { unpublished studies }\end{array}$ & $\begin{array}{l}\text { Number of } \\
\text { patients enrolled } \\
\text { in unpublished } \\
\text { randomised studies }\end{array}$ \\
\hline Diagnostic criteria & 11 & $10(91 \%)$ & $2(100 \%)$ & 500 & 0 \\
\hline Antibiotic treatment & 11 & $7(64 \%)$ & $4(57 \%)$ & $15275^{\star}$ & 275 \\
\hline Other & 9 & $5(56 \%)$ & $2(59 \%)$ & $80300 \dagger$ & 300 \\
\hline
\end{tabular}

Outliers:

*Study NCT02311452 was registered as completed on ClinicalTrials.gov and having enrolled 15000 patients.

†Studies NCT02018016 and NCT02017951 were reported as completed and having enrolled 40000 patients each. 
Table 2A Characteristics of unpublished clinical trials $(n=19)$

\begin{tabular}{|c|c|c|c|c|}
\hline Study identifier & Study issue & Study design & Enrolment & Completion date \\
\hline NCT01054417 & Surgical procedure & Observational & 142 & July 2011 \\
\hline NCT01678365 & Antibiotic treatment & Interventional & 43 & October 2009 \\
\hline NCT02730585 & Diagnostic criteria & Observational & 500 & December 2013 \\
\hline NCT01067937 & Pain management & Interventional & 891 & April 2011 \\
\hline NCT02673528 & Surgical procedure & Observational & 451 & January 2016 \\
\hline NCT01967745 & Surgical procedure & Observational & 100 & September 2013 \\
\hline NCT02625987 & Surgical procedure & Interventional & 200 & September 2015 \\
\hline NCT02580487 & Pain management & Observational & 178 & October 2015 \\
\hline NCT00554008 & Surgical procedure & Interventional & 400 & January 2011 \\
\hline NCT02714023 & Other & Interventional & 240 & September 2015 \\
\hline NCT01424631 & Surgical procedure & Interventional & 2 & Not specified \\
\hline NCT02018016 & Other & Observational & 40000 & August 2013 \\
\hline NCT02017951 & Other & Observational & 40000 & August 2013 \\
\hline NCT02687217 & Other & Interventional & 60 & May 2013 \\
\hline NCT01515293 & Surgical procedure & Interventional & 184 & Not specified \\
\hline
\end{tabular}

Close of database 3 May 2016.

Our analysis demonstrated that $37 \%$ of registered completed studies in appendicitis involving children remain unpublished. Results for the majority of interventional studies $(66 \%)$ and randomised studies $(60 \%)$ were publicly available. In contrast, most observational studies remained unpublished. Unpublished studies account for data of 98673 patients overall. However, three large retrospective studies were outliers in this group: two studies were designed to compare outcomes of appendectomies between hospitals in 40000 patients each (studies NCT02018016 and NCT02017951). The third study included data from 15000 children to compare oral and intravenous treatment in appendicitis and other inflammatory conditions (study NCT02311452). Without these

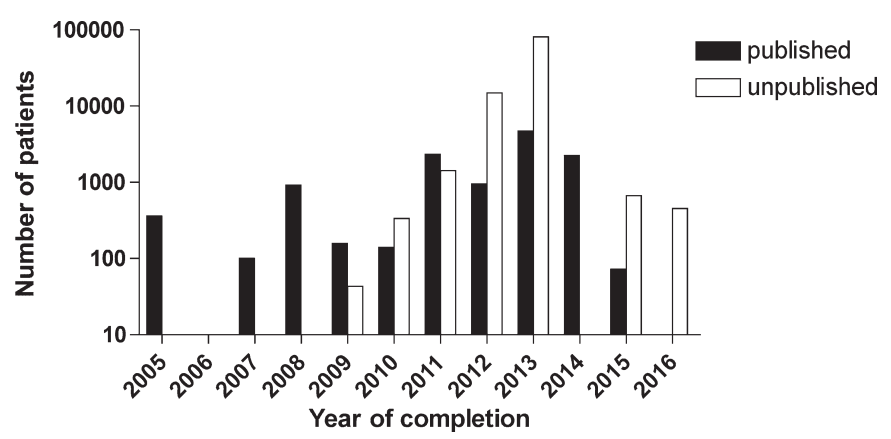

Figure 3 Published and unpublished paediatric appendicitis studies: number of patients by year of completion (log scale). Three studies were outliers (see tables 1 and $2 \mathrm{~A}$ ). three studies, unpublished studies contained data from 3673 patients.

While the majority of trials, that is, $\mathrm{n}=43 / 52$ (83\%) assessed the four important controversial key issues, the availability of answers to these questions varied: diagnostic studies were most rigorously published, with $91 \%$ of all trials published, data on surgical procedures, antibiotic and pain management were less transparent. The lack of transparency may lead to an ongoing ambiguity in the field. All industry-sponsored or cosponsored studies were published which may indicate that industry compliance with FDAAA — which mandates publication within 1 year after trial completion- is high. ${ }^{20}$ Publication rates varied between countries of sponsor/collaborator (table 3).

Without overwhelming evidence for or against an intervention, most surgeons may remain faithful to their successfully proven routine; especially, regarding new surgical techniques or alternative treatment options like antibiotic treatment. New concepts in diagnostic criteria and pain management may be more easily adopted. We speculate that professional mentality may play a role, too, and that it might be possible that less traditional attendings may be more open for new developments and try to adopt new surgical techniques, diagnostic criteria and treatment options like antibiotics instead of surgery in selected patients. In general, scientific uncertainty and ambiguity may explain different approaches in surgery. In order to adopt new evidence, it may be 
Table 2B Characteristics of published clinical trials $(n=33)$

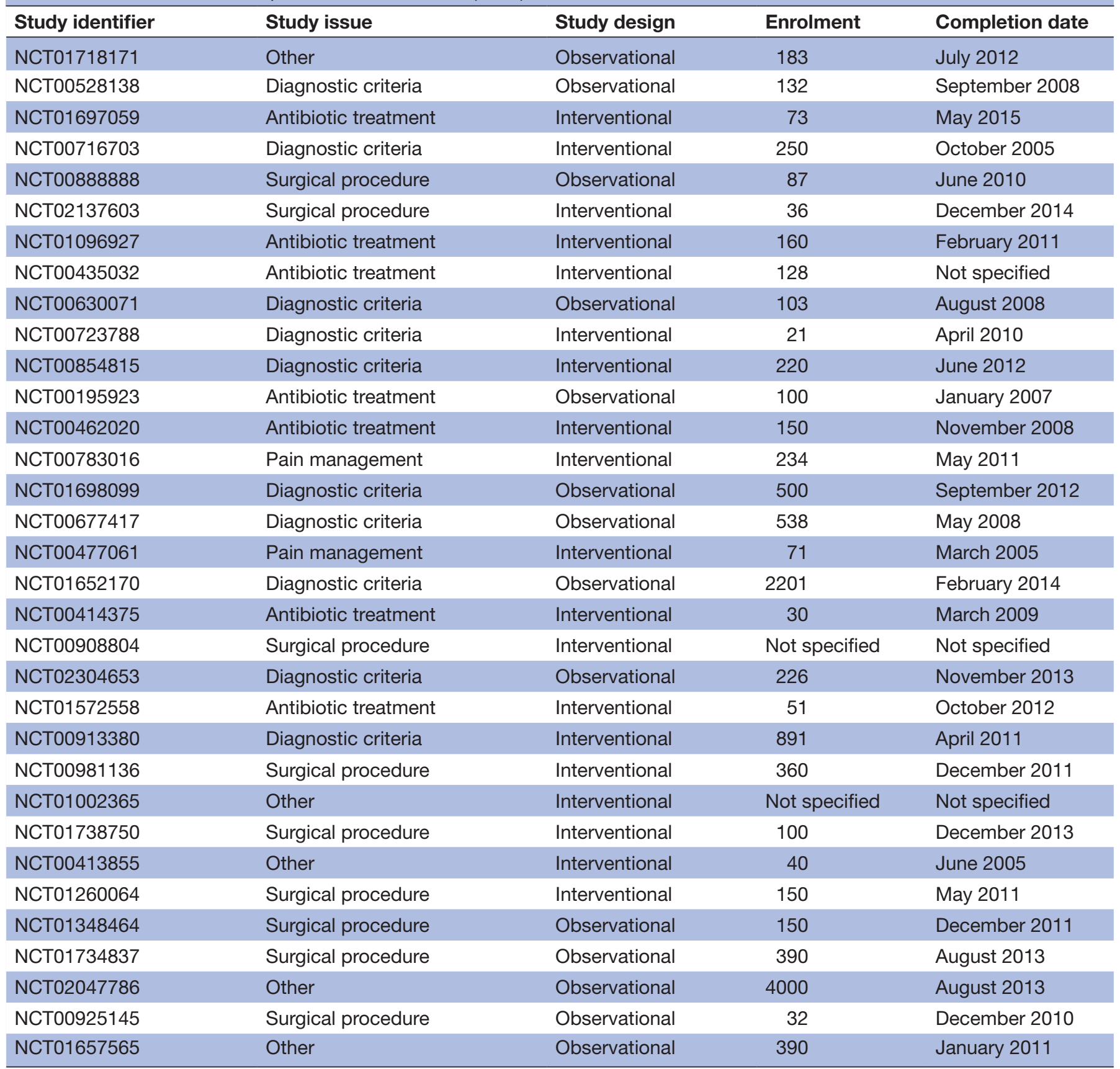

Close of database 3 May 2016.

appropriate to update and disseminate internal guidelines regularly.

Median time-to-publication in the present study was 24 months. This was twice as long as the deadline of 12 months after completion mandated by FDAAA. In 2007, Hopewell et al reviewed time-to-publication as time between start of trial and time of publication and found that results of positive studies were available after $4-5$ years and negative studies after $6-8$ years. ${ }^{21}$

There was a trend towards improvement in terms of timely public availability of results. Similar issues exist in other challenging areas of paediatric medicine, such as epilepsy, autism and liver transplantation. ${ }^{15-1722}$

\section{Limitations and directions for future research}

This study has several limitations. Clinical trial registration databases other than ClinicalTrials.gov were not analysed. Unregistered clinical studies were not captured by the present study method. This present analysis relies on accurate data entry into ClinicalTrials.gov. ${ }^{20}$ We made all efforts to avoid a study being classified as unpublished by searching the two major medical literature databases, PubMed and Google Scholar, and by contacting investigators directly. Reasons why studies remain unpublished were reviewed by Song et al who identified non-submission of study results due to lack of time or low priority and fear of being rejected by journals as the predominant 
Table 3 Published $(n=33)$ and unpublished $(n=19)$ completed studies on paediatric appendicitis by country

\begin{tabular}{lcl}
\hline Countries & $\begin{array}{l}\text { Published } \\
\text { studies } \\
\text { (N) }\end{array}$ & $\begin{array}{l}\text { Unpublished } \\
\text { studies } \\
\text { (N) }\end{array}$ \\
\hline Chile & 3 & 0 \\
\hline Croatia & 0 & 1 \\
\hline Denmark & 2 & 0 \\
\hline Egypt & 0 & 1 \\
\hline Finland & 1 & 1 \\
\hline France & 0 & 1 \\
\hline Germany & 3 & 0 \\
\hline India & 0 & 1 \\
\hline Iran & 1 & 0 \\
\hline Israel & 1 & 1 \\
\hline Italy & 1 & 0 \\
\hline Mexico & 0 & 1 \\
\hline Netherlands & 1 & 1 \\
\hline Scotland & 1 & 2 \\
\hline South Korea & 3 & 0 \\
\hline Spain & 0 & 2 \\
\hline Sweden & 1 & 0 \\
\hline Tunisia & 0 & 1 \\
\hline Turkey & 1 & 0 \\
\hline USA & 13 & 1 \\
\hline USA/Germany & 1 & 1 \\
\hline
\end{tabular}

issue. ${ }^{23}$ In particular, researchers may encounter difficulties to publish their results, such as lack of interest of the journal or multiple rejections by different journals. While multiple unsuccessful attempts to publish a manuscript in high-impact journals may lead to publication delay, ${ }^{24}$ the ClinicalTrials.gov webpage allowing timely posting of topline clinical trial results is easily accessible and should be helpful in early dissemination of research findings. Six studies were completed less than a year before close of database, which may be too short to publish in

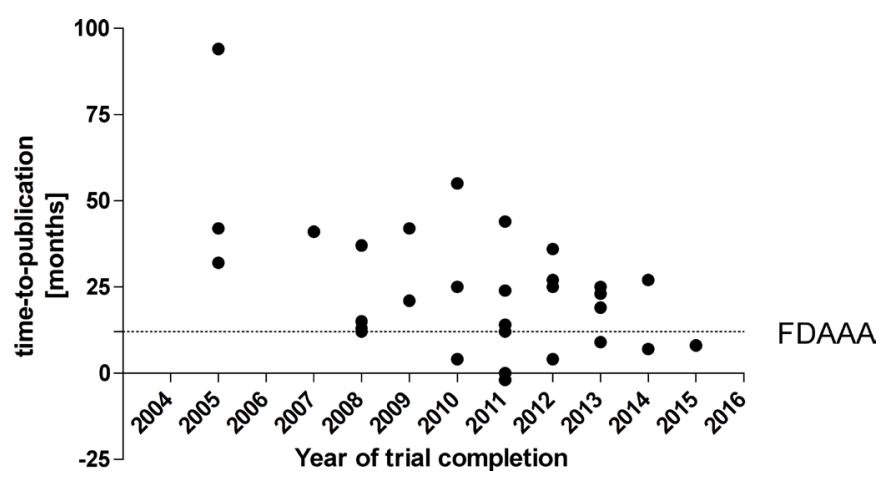

Figure 4 Time-to-publication of paediatric appendicitis studies. 'FDAAA' indicates the time line mandated by the Food and Drug Administration Amendments Act of $2007 .{ }^{20}$ a peer-reviewed journal, however posting the results on ClinicalTrials.gov would have been possible.

The present data emphasise the necessity to sensitise paediatric and paediatric surgery residents towards awareness of possible publication bias in paediatric appendicitis. In addition, these data serve as baseline for future publication monitoring. ${ }^{25}$ We strongly encourage publication of all trial results. In particular, negative data are important in order to prevent subjects being exposed to unnecessary, repeated research. In addition, negative data can be helpful in identifying and correcting perpetual scientific misconception in medical practice, exemplified by the case of fluid replacement with hydroxyethyl starch in critical care patients where data in meta-analyses of clinical trials were unable to further support a positive risk-benefit-ratio for this previously widely used intervention. ${ }^{26} 27$ The present data serve as quantitative baseline for data transparency in paediatric appendicitis, and it would be of high interest to analyse progress on this issue in the future.

\section{CONCLUSION}

These data raise awareness that despite the importance of appendicitis in clinical practice for the paediatric surgeon, there remains a certain degree of scientific uncertainty due to unpublished clinical trial results with room for improvement in the future. Therefore, biases may exist in the current literature. These data are helpful in framing the shifting paradigms in paediatric appendicitis because they add transparency to the debate.

Contributors Substantial contributions to conception or design of the work, or the acquisition, analysis, or interpretation of data for the work: TB, MB, GFH, MR. Drafting of the work or revising it critically for important intellectual content: TB, MB, GFH, MR. Final approval of the version to be published: TB, MB, GFH, MR. Agreement to be accountable for all aspects of the work in ensuring that questions related to the accuracy or integrity of any part of the work are appropriately investigated and resolved: TB, MB, GFH, MR.

Funding We acknowledge financial support by Deutsche Forschungsgemeinschaft within the funding programme Open Access Publishing, by the Baden-Württemberg Ministry of Science, Research and the Arts and by Ruprecht-Karls-Universität Heidelberg.

Competing interests MR received consultancy fees or research grants from Alexion, GSK, Oxyrane and Shire unrelated to the subject of this project.

Patient consent Not required.

Provenance and peer review Not commissioned; externally peer reviewed.

Data sharing statement All data are in the manuscript.

Open access This is an open access article distributed in accordance with the Creative Commons Attribution Non Commercial (CC BY-NC 4.0) license, which permits others to distribute, remix, adapt, build upon this work non-commercially, and license their derivative works on different terms, provided the original work is properly cited, appropriate credit is given, any changes made indicated, and the use is non-commercial. See: http://creativecommons.org/licenses/by-nc/4.0/.

\section{REFERENCES}

1. St Peter SD, Sharp SW, Holcomb GW, et al. An evidence-based definition for perforated appendicitis derived from a prospective randomized trial. J Pediatr Surg 2008;43:2242-5. 
2. Addiss DG, Shaffer N, Fowler BS, et al. The epidemiology of appendicitis and appendectomy in the United States. Am J Epidemiol 1990;132:910-25.

3. Rentea RM, Peter SDS, Snyder CL. Pediatric appendicitis: state of the art review. Pediatr Surg Int 2017;33:269-83.

4. Alvarado A. A practical score for the early diagnosis of acute appendicitis. Ann Emerg Med 1986;15:557-64.

5. Samuel M. Pediatric appendicitis score. J Pediatr Surg 2002;37:877-81.

6. Boettcher M, Breil T, Günther P. The Heidelberg appendicitis score simplifies identification of pediatric appendicitis. Indian J Pediatr 2016;83:1093-7.

7. Svensson JF, Patkova B, Almström M, et al. Nonoperative treatment with antibiotics versus surgery for acute nonperforated appendicitis in children: a pilot randomized controlled trial. Ann Surg 2015;261:67-71.

8. Tanaka Y, Uchida H, Kawashima H, et al. Long-term outcomes of operative versus nonoperative treatment for uncomplicated appendicitis. J Pediatr Surg 2015;50:1893-7.

9. Huang L, Yin Y, Yang L, et al. Comparison of antibiotic therapy and appendectomy for acute uncomplicated appendicitis in children. JAMA Pediatr 2017;171:426.

10. Jen HC, Shew SB. Laparoscopic versus open appendectomy in children: outcomes comparison based on a statewide analysis. $J$ Surg Res 2010;161:13-17.

11. St Peter SD, Adibe OO, Juang D, et al. Single incision versus standard 3-port laparoscopic appendectomy: a prospective randomized trial. Ann Surg 2011;254:586-90.

12. Zhang Z, Wang Y, Liu R, et al. Systematic review and meta-analysis of single-incision versus conventional laparoscopic appendectomy in children. J Pediatr Surg 2015;50:1600-9.

13. Robb AL, Ali S, Poonai N, et al. Pain management of acute appendicitis in Canadian pediatric emergency departments. CJEM 2017:19:417-23.

14. Goyal MK, Kuppermann N, Cleary SD, et al. Racial disparities in pain management of children with appendicitis in emergency departments. JAMA Pediatr 2015;169:996-1002.

15. Breil T, Wenning D, Teufel U, et al. An assessment of publication status of pediatric liver transplantation studies. PLoS One 2016;11:e0168251.
16. Lampert A, Hoffmann GF, Ries M. Ten Years after the International Committee of Medical Journal Editors' Clinical Trial Registration Initiative, One Quarter of Phase 3 Pediatric Epilepsy Clinical Trials Still Remain Unpublished: A Cross Sectional Analysis. PLoS One 2016;11:e0144973.

17. Mechler K, Hoffmann GF, Dittmann RW, et al. Defining the hidden evidence in autism research. Forty per cent of rigorously designed clinical trials remain unpublished - a cross-sectional analysis. Int $J$ Methods Psychiatr Res 2017;26.

18. Vandenbroucke JP, von Elm E, Altman DG, et al. Strengthening the Reporting of Observational Studies in Epidemiology (STROBE): explanation and elaboration. PLoS Med 2007;4:e297.

19. Pearn J. Publication: an ethical imperative. BMJ 1995;310:1313-5.

20. FDAAA. Sec. 801. Expanded clinical trial registry data bank 2007. 2007. http://www.gpo.gov/fdsys/pkg/PLAW-110pub/85/html/PLAW110publ85.htm

21. Hopewell S, Clarke MJ, Stewart L, et al. Time to publication for results of clinical trials. Cochrane Database Syst Rev 2007;279:MR000011.

22. Anderson ML, Chiswell K, Peterson ED, et al. Compliance with results reporting at ClinicalTrials.gov. N Engl J Med 2015;372:1031-9.

23. Song F, Loke Y, Hooper L. Why are medical and health-related studies not being published? A systematic review of reasons given by investigators. PLoS One 2014;9:e110418.

24. Evoniuk G, Mansi B, DeCastro B, et al. Impact of study outcome on submission and acceptance metrics for peer reviewed medical journals: six year retrospective review of al completed GlaxoSmithKline human drug research studies. BMJ 2017;357:j1726.

25. Casadevall A, Ellis LM, Davies EW, et al. A framework for improving the quality of research in the biological sciences. MBio 2016;7:e01256-16.

26. Hartog CS, Welte T, Schlattmann P, et al. Fluid replacement with hydroxyethyl starch in critical care--a reassessment. Dtsch Arztebl Int 2013;110:443-50.

27. Serpa Neto A, Veelo DP, Peireira VG, et al. Fluid resuscitation with hydroxyethyl starches in patients with sepsis is associated with an increased incidence of acute kidney injury and use of renal replacement therapy: a systematic review and meta-analysis of the literature. J Crit Care 2014:29:185.e1-185.e7. 